\title{
Isothermal Decomposition Kinetics of Nickel (II) Hydroxide Powder
}

\author{
C.S. Carney ${ }^{1,2,3}$, R.E. Chinn ${ }^{1}$, Ö.N. Doğan ${ }^{1}$ and M.C. Gao ${ }^{1,2}$ \\ 1. National Energy Technology Laboratory, U.S. Dept. of Energy, Albany, Oregon, USA \\ 2. AECOM, P.O. Box 1959, Albany, Oregon, USA \\ 3. Corresponding author, (Casey.Carney@CONTR.NETL.DOE.GOV, +1 541-918-8096).
}

\begin{abstract}
Nickel (II) hydroxide powder was investigated by thermogravimetry for isothermal decomposition kinetics and verification of the $\mathrm{Ni}-\mathrm{O}-\mathrm{H}$ ternary phase diagram at low temperatures. The activation energy and frequency factor were measured as $E_{a}=134 \mathrm{~kJ} / \mathrm{mol}$ and $A=1.27 \times 10^{10} \mathrm{~s}^{-1}$, respectively. The validity of the first-order random nucleation model was confirmed, as opposed to diffusion and or moving-boundary models. The dependence of TGA results on specimen size was noted. The $\mathrm{Ni}-\mathrm{Ni}(\mathrm{OH})_{2}-\mathrm{NiO}$ phase triangle was confirmed. Accordingly, a thermodynamic description of the system was established in the Ni-rich corner, and the isotherm at room temperature is calculated.
\end{abstract}

Keywords: nickel hydroxide, thermal decomposition kinetics, oxide materials, solid state reactions, kinetics, thermal analysis, $x$-ray diffraction

\section{Introduction}

Oxides, hydroxides and oxyhydroxides of nickel are of interest as electrode materials for rechargeable batteries [1-8]. Nickel (II) hydroxide occurs in at least three polymorphs, $\alpha, \beta$ and $\gamma$, and transitions with nickel (III) oxyhydroxide in a redox reaction at battery electrodes during charging and discharging. The behavior, transformation, and reactions of nickel hydroxide would thus be of interest for these battery electrode applications. Nickel hydroxide is often used as a precursor for nanosheet and nanostructured nickel oxide [9], which exhibit unique properties including: magnetic and photo catalytic [10-13], optical absorbance [14], water treatment [15], and gas sensing [16]. For these applications, the desired unique properties of the nickel oxide often greatly depend upon physical, structural, morphological, and chemical characteristics of the nickel oxide material itself. A thorough understanding of the kinetic rates, mechanisms, and pathways governing the thermal decomposition of nickel hydroxide would be required in order to be able to carefully control the physical characteristics of the product nickel oxide. 
The thermal decomposition of hexagonal $\beta-\mathrm{Ni}(\mathrm{OH})_{2}$ (theophrastite) to face-centered cubic $\mathrm{NiO}$ (bunsenite) proceeds as

$\mathrm{Ni}(\mathrm{OH})_{2}(s) \rightarrow \mathrm{NiO}(s)+\mathrm{H}_{2} \mathrm{O}(g)$

As the above reaction is a solid state decomposition process, the reaction rate is generally expressed as

$\frac{d \alpha}{d t}=A e^{-(E a / R T)} F(\alpha)$

where $\alpha$ is the mass fractional conversion, $A$ is the kinetic pre-exponential frequency factor, $E_{a}$ is the activation energy, $R$ is the ideal gas law constant, $T$ is the sample temperature, $t$ is time, and $F(\alpha)$ is the kinetic model function chosen to represent the decomposition. The common solid state reaction models considered for this study have been thoroughly defined and derived by Galwey and Brown [17], and the model list has been concisely presented by Khawam and Flanagan [18].

For the isothermal experiments, the integrated form of Eqn. (2) was utilized in order to select which decomposition model best fit the TGA decomposition data.

$G(\alpha)=A e^{-(E a / R T) t}$

where $G(\alpha)$ is the integrated form of $F(\alpha)$. Corresponding forms of $G(\alpha)$ can also be found in Khawam and Flanagan [18]. A potentially valid decomposition model will result in a straight line when $G(\alpha)$ is plotted vs time. Seventeen thermal decomposition models are listed in the previous reference and were considered for a potential fit to the experimental data. While the decomposition of nickel hydroxide to nickel oxide has been verified numerous times, only a few kinetic studies of the decomposition can be found in the literature. There is no general agreement on the mechanism for nickel hydroxide thermal decomposition, although reported activation energies are somewhat close in value. The spread in reported activation energies is at least in part due to differences in obtainment and preparation of the nickel hydroxide precursor, often resulting in differences of morphology and structure, which is known to have significant effects on the thermal decomposition process.

El-Salaam and Hassan [19] conducted isothermal decomposition studies and proposed a contracting volume mechanism with $E_{a}=119 \mathrm{~kJ} / \mathrm{mol}$. Their sample sizes were rather large, $500 \mathrm{mg}$ when compared with the present and other studies. Hazell and Irving [20] also used a rather large sample size $\left(340 \mathrm{mg}\right.$ ) for their isothermal studies, proposing a contracting area mechanism with $E_{a}=95$ $\pm 4 \mathrm{~kJ} / \mathrm{mol}$ for conversions less than $60 \%$. They observed that product water retention became significant at higher conversions values, thus making kinetic fitting difficult. Swaddle and Wong [21] used two types of nickel hydroxide in their isothermal kinetic studies: unripened (less crystalline, more attached water) and ripened (highly crystalline, less attached water). The authors found that both contracting area and volume mechanisms fit the data equally well (in part due to the authors essentially needing to use the incubation time as a fit parameter). For unripened (wet) nickel hydroxide, $E_{a}=114$ 
$\mathrm{kJ} / \mathrm{mol}$, for ripened (dry) nickel hydroxide, $E_{a}=132 \mathrm{~kJ} / \mathrm{mol}$. The highest literature activation energies was reported as $177 \mathrm{~kJ} / \mathrm{mol}$ by Gabr et al. [22] for isothermal dynamic air conditions in the range of 250$350^{\circ} \mathrm{C}$. An Avrami-Erofeyev nucleation and growth mechanism was proposed, although the geometrydefining Avrami-Erofeyev exponent was not provided.

Logvinenko et al. [23] performed non-isothermal kinetic studies (heating rates of $5-20^{\circ} \mathrm{C} / \mathrm{min}$ ) under helium flow utilizing the model-free Ozawa-Flynn-Wall technique. They found that dehydration of surface water occurred below $157^{\circ} \mathrm{C}$, and thus limited their kinetic study to temperatures above $157^{\circ} \mathrm{C}$. A stable activation energy value of $100 \pm 4 \mathrm{~kJ} / \mathrm{mol}$ was found in the conversion range of $15-80 \%$. The reaction curve shapes led the authors to conclude that the decomposition mechanism was either first-order or contracting geometry. Tang et al. [14] performed non-isothermal kinetic studies, similar to ASTM E698 [24] and E2041 [25], of nickel hydroxide nanoparticles (heating rates of $2-22^{\circ} \mathrm{C} / \mathrm{min}$ ) under air flow also utilizing a model-free kinetic analysis approach. The shape of the reaction curve indicated a first-order decomposition and $E_{a}$ was calculated to be $118 \mathrm{~kJ} / \mathrm{mol}$. The nanoparticles may have absorbed some $\mathrm{CO}_{2}$ from atmospheric exposure, thus influencing the decomposition process. Hazel and Irving [20] performed additional non-isothermal kinetic experiments using Doyle's model free technique. Experiments were performed in both air and vacuum, although with differing methods of nickel hydroxide preparation, thus making direct comparisons more difficult. Thermal decomposition in air $\left(\mathrm{NaOH} / \mathrm{NiNO}_{3}\right.$ preparation route) resulted in activation energies ranging from $72-101 \mathrm{~kJ} / \mathrm{mol}$, while vacuum decomposition (boiling nickel amine preparation route resulting in a more crystalline precursor) yielded activation energies of $89-110 \mathrm{~kJ} / \mathrm{mol}$. The authors note that difficulties in controlling the particle size distribution of nickel hydroxide between kinetic runs likely led to the reported spread in activation energies.

In addition to the isothermal decomposition kinetics of $\mathrm{Ni}(\mathrm{OH})_{2}$, this study also addresses some of the uncertainties in the Ni-rich corner of the ternary $\mathrm{Ni}-\mathrm{O}-\mathrm{H}$ phase diagram at low temperatures. It is well known that environmental degradation of alloys (e.g. steels and $\mathrm{Ni}$-based alloys) is accelerated in steam $\left(\mathrm{H}_{2} \mathrm{O}\right)$ containing environments [26]. In order to gain a fundamental understanding of the degradation mechanisms, computational efforts are required to develop a self-consistent thermodynamic database for a model Ni-Fe-Al-O-H alloy system using the CALPHAD (CALculations of PHAse Diagrams) method. Such database development requires experimental phase equilibria of subsystems as inputs. Several compounds are reported to be stable in the $\mathrm{Ni}-\mathrm{H}-\mathrm{O}$ system at lower temperatures, namely, $\mathrm{Ni}(\mathrm{OH})_{2}, \mathrm{HNi}_{2} \mathrm{O}_{3}$ and $\mathrm{HNiO}_{2}$. They may not impact the degradation of $\mathrm{Ni}$ alloys at high temperatures, but may be important to understanding corrosion behavior of $\mathrm{Ni}$ alloys in presence of water vapor. Due to the facility limitation in fabricating $\mathrm{HNi}_{2} \mathrm{O}_{3}$ and $\mathrm{HNiO}_{2}$, the present study aims to examine the ternary $\mathrm{Ni}-\mathrm{O}-\mathrm{H}$ phase diagram in the Ni-rich corner at lower temperatures. Huggins [27] constructed a diagram of Gibbs triangles for the Ni-O-H system based on available charging and discharging of nickel electrodes experimental data, which is shown in Figure 1. The diagram Huggins constructed is not an isotherm and there have been no further experimental validation efforts. Some questions that arise from the work are: (1) Is the tie triangle Huggins suggested correct? (2) Are there other nickel hydroxides besides $\mathrm{Ni}(\mathrm{OH})_{2}$ in the Ni-rich corner? (3) What are the phase relationships 
among $\mathrm{Ni}, \mathrm{NiO}, \mathrm{Ni}(\mathrm{OH})_{2}$, liquid $\mathrm{H}_{2} \mathrm{O}$, and $\mathrm{H}_{2}$ gas? This study will attempt to address some of these issues by annealing three nominal compositions: $\mathrm{Ni}_{50} \mathrm{O}_{40} \mathrm{H}_{10}, \mathrm{Ni}_{50} \mathrm{O}_{30} \mathrm{H}_{20}$, and $\mathrm{Ni}_{70} \mathrm{O}_{20} \mathrm{H}_{10}$.

\section{Experimental}

Decomposition kinetics of $\mathrm{Ni}(\mathrm{OH})_{2}$ (Alfa Aesar, 98.4\%, 325 mesh) were studied with a thermogravimetric analyzer (TGA, STA429CD, Netzsch-Gerätebau GmbH), in a static $99.999 \%$ helium atmosphere with a $90 \mathrm{~mm}^{3}$ tungsten crucible. The small size of this TGA crucible has been designed to minimize internal sample temperature gradients to the point of being negligible. Two sets of kinetic experiments with differing sample masses were performed and are referred to as Isothermal-A and Isothermal-B. The Isothermal-A data set used a nickel hydroxide precursor with a mass of 10-11 mg, with a range of hold temperatures between $190^{\circ} \mathrm{C}$ and $270^{\circ} \mathrm{C}$. The Isothermal-B data set used a nickel hydroxide precursor with a mass of $90-110 \mathrm{mg}$, with a range of hold temperatures between $190^{\circ} \mathrm{C}$ and $280^{\circ} \mathrm{C}$. For these isothermal experiments, the TGA was rapidly heated at $20^{\circ} \mathrm{C} / \mathrm{min}$ to the desired temperature, and then held at that temperature for a maximum of 48 hours. Kinetic data was only taken once the system temperature had achieved a constant value. Three non-isothermal runs with a $5^{\circ} \mathrm{C} / \mathrm{min}$ heating rate were conducted for additional analysis: $\mathrm{Ni}(\mathrm{OH})_{2}$ with sample masses of $10 \mathrm{mg}$ and $87 \mathrm{mg}$, and one run with a $\mathrm{NiO}$ precursor to investigate any potential reaction between product $\mathrm{NiO}$ and the crucible.

Annealing experiments of the three compositions of the $\mathrm{Ni}-\mathrm{O}-\mathrm{H}$ system starred in Figure 1 were conducted. The three nominal bulk compositions were: $\mathrm{Ni}_{50} \mathrm{O}_{40} \mathrm{H}_{10}, \mathrm{Ni}_{50} \mathrm{O}_{30} \mathrm{H}_{20}$, and $\mathrm{Ni}_{70} \mathrm{O}_{20} \mathrm{H}_{10}$. Each mixture was prepared by mixing appropriate masses of the following 325 mesh powders: Ni (Alfa Aesar 99.8\% metals basis), $\mathrm{Ni}(\mathrm{OH})_{2}$, and $\mathrm{NiO}$ (ESPI Metals, 99.9\%) in a vibratory shaker. Once mixed, a hydraulic press at $138 \mathrm{MPa}$ compacted the powders into discs. Powders were mixed and pressed in a glove bag under inert flow to minimize oxidation of the powders/discs. Each pressed disc was broken into three pieces so that each composition could be annealed at three temperatures: 210,220 , and $230^{\circ} \mathrm{C}$. Annealing took place in a three zone control tube furnace under argon flow for 7 days. Each zone was set to one of the above temperatures and each zone had an individual monitoring thermocouple to ensure accuracy and stability. In this manner, annealing for all nine samples (three compositions, three temperatures for each composition) was able to take place simultaneously. Samples were loaded and removed from the furnace under inert flow as well.

X-ray diffraction scans were obtained of samples before and after annealing and TGA decomposition testing with an Ultima III (Rigaku Americas Corp.) using Cu K-alpha radiation. Micrographs of all samples were generated with an FEI Inspect F50 SEM.

\section{Results and Discussion}

The TGA mass traces for the non-isothermal $\mathrm{Ni}(\mathrm{OH})_{2}$ experiments exhibit three reaction phases. The initial reaction phase, below $\sim 250^{\circ} \mathrm{C}$, corresponds to the fairly slow release of surface and adsorbed 
water. From the TGA traces, this surface water content is in the range of 1.5-3.0\%, determined by intersection of tangents to the two curve slopes. The second phase of the reaction is the rapid decomposition of the majority of the nickel hydroxide, occuring in the range of $250-340^{\circ} \mathrm{C}$. The third reaction phase, occuring above $340^{\circ} \mathrm{C}$, is continued decomposition, but with a much slower reaction rate (than the bulk of the decomposition) as the reaction approaches full conversion. While NiO can react with the tungsten crucible to form $\mathrm{NiWO}_{4}$ at elevated temperatures approaching $1000^{\circ} \mathrm{C}$, Figure 2 indicates that no $\mathrm{NiO}$ reaction occurs up to $600^{\circ} \mathrm{C}$, and thus will not occur when $\mathrm{Ni}(\mathrm{OH})_{2}$ is used as the precursor for the kinetics experiments that occur below to $600^{\circ} \mathrm{C}$. These $\mathrm{Ni}(\mathrm{OH})_{2}$ experiments were repeated with two sample loading masses: $87 \mathrm{mg}$ and $10 \mathrm{mg}$. While the reaction rates between the two samples appear to be similar, there is a longer induction/surface water removal phase before nickel hydroxide decomposition initiates for the larger sample mass. This observed reaction initiation delay could be due to longer water outlet pathway sizes or longer heating times found in the larger nickel hydroxide sample. The nearly-zero slope of the $\mathrm{NiO}$ curve in Figure 2 compared to the slope of the right hand flat segment of the $\mathrm{Ni}(\mathrm{OH})_{2}$ curves (where the $\mathrm{Ni}(\mathrm{OH})_{2}$ has decomposed to $\mathrm{NiO}$ ) suggests the $\mathrm{Ni}(\mathrm{OH})_{2}$ has not been entirely converted and is still slowly decomposing above $300^{\circ} \mathrm{C}$.

By mass balance, the complete decomposition of pure $\mathrm{Ni}(\mathrm{OH})_{2}$ to $\mathrm{NiO}$ results in 80.6 mass\% remaining; that is, the bonded $\mathrm{H}_{2} \mathrm{O}$ content is $19.4 \%$ of the $\mathrm{Ni}(\mathrm{OH})_{2}$. Based upon the non-isothermal experiments that were able to separate surface water desorption from the bulk decomposition of Eqn. (1), the surface water content was taken to be $2.2 \%$. Fractional conversion can thus be computed from the TGA mass \% remaining trace by

$$
\alpha=\frac{\text { moles }_{\mathrm{Ni}(\mathrm{OH})_{2}}^{\text {reacted }}}{\text { moles }_{\mathrm{Ni}(\mathrm{OH})_{2}}^{0}}=\frac{\text { mass } \%-\text { mass }_{\text {surface water }}}{100-\text { mass }_{\text {surface water }}}=\frac{\text { mass } \%-2.2}{97.8}
$$


For isothermal decomposition the reaction rate is temperature sensitive within the $200-300^{\circ} \mathrm{C}$ range, as can be observed in Figure 3. The respective time scales show that the decomposition progressed faster for the smaller $10 \mathrm{mg}$ nominal sample size (Isothermal-A) than for the $100 \mathrm{mg}$ nominal sample size (Isothermal-B). For both data sets, the reaction rapidly proceeds towards near completion above $250^{\circ} \mathrm{C}$. The flattening of the right-end sections of the higher-temperature curves in Figure 3 occurs slightly before full conversion ( $90 \%)$, indicating a reaction that has severely slowed, but not yet gone to completion - as was also observed in the non-isothermal case of Figure 2.

The phase contents of the $100 \mathrm{mg}$ nominal sample size powders identified by XRD are shown in Figure 4. Nickel oxide was not present in the initial, as-received powder, and no nickel hydroxide was present after the $280^{\circ} \mathrm{C}$ hold. Both phases were present after the $190^{\circ} \mathrm{C}$ hold, with 12.0 mass $\% \mathrm{NiO}$ by Rietveld refinement [28], compared to $22.4 \%$ by TGA. The nearly eleven percentage point difference between the Rietveld XRD and TGA conversion calculations is probably due to the incomplete conversion of $\mathrm{Ni}(\mathrm{OH})_{2}$ to $\mathrm{NiO}$, and diffraction peak overlap. The broad peaks in the as-received $\mathrm{Ni}(\mathrm{OH})_{2}$ precursor XRD spectrum of Figure 4 suggest a potential deviation from expected stoichiometry, perhaps due to the observed surface adsorption of water. The broad peaks in the $280^{\circ} \mathrm{C}$ spectrum of Figure 4 suggest either incomplete conversion (as observed in Figure 3 ) or high strain as a result of the $\mathrm{H}$ and $\mathrm{O}$ atoms diffusing away from the $\mathrm{Ni}(\mathrm{OH})_{2}$ lattice.

Figure 5 presents $\mathrm{SEM}$ images of the $\mathrm{Ni}(\mathrm{OH})_{2}$ precursor, partially converted, and nearly fully converted Isothermal-B (100 mg nominal sample size) TGA product particles. There is virtually no difference between the three powders in regard to shape, size, or morphology, likely due to the relatively low decomposition temperatures not favorable for sintering. There does not appear to be any cracking or other surface changes due to the reaction itself and evolved product water vapor. These imaging observations do not support any form of a moving boundary reaction mechanism.

For both data sets, 17 potential solid state decomposition models [18] were fitted against the experimental data. The classes of models investigated include: contracting area/volume, diffusion limited, power law, nucleation and growth, and order of reaction. Model validity was tested by plotting the $G(\alpha)$ model functions vs time. As per Eqn. (3), this plot of $G(\alpha)$ vs time will result in a straight line for any models that satisfactorily fit the data. Another graphical method than can help select/reject potential kinetic model functions is to plot the reaction rate vs conversion. Each various kinetic model mechanism class will have a characteristic reaction rate $\left(\frac{d \alpha}{d t}\right)$ vs $\alpha$ curve shape [18]. Figure 6 shows these experimental curves for both isothermal data sets. These analyses will be discussed for the two data sets tested.

\subsection{Isothermal-A Model Fitting (10 mg sample mass)}

Of the solid state models tested, only the first-order decomposition kinetics was observed to fit the Isothermal-A experimental data - the smaller sample size ( $10 \mathrm{mg}$ ). Based upon the shape of the reaction rate curves, first-order kinetics provided the only acceptable fit. The first-order kinetic fit was valid in the $20-70 \%$ conversion range, as can be observed by the linear plots indicative of first-order kinetics within that conversion range in Figure 6 . Outside of the $20-70 \%$ conversion range, there were 
initial induction and final deceleratory phases that did not obey the first-order kinetics. This final deceleratory region was also observed for the non-isothermal decomposition (Figure 2), and is likely due to either product water buildup in the lattice suppressing further reaction or the limited number of remaining nickel hydroxide reaction sites as full conversion is approached. For a first-order model, Eqn. (2) appears as

$\frac{d \alpha}{d t}=A e^{-(E a / R T)}(1-\alpha)$

Thus, a plot of $\left(\frac{d \alpha}{d t}\right)$ vs $\alpha$ yields a slope of negative reaction rate $k$ where

$k=A e^{-(E a / R T)}$

Taking the natural log of Eqn. (6)

$\ln k=\ln A-\frac{E_{a}}{R} \times \frac{1}{T}$

allows for the computation of the activation energy by plotting the linear $\ln \mathrm{k}$ vs inverse temperature (Arrhenius plot), which yields a slope equal to $\frac{-E_{a}}{R}$ and a y-intercept of $\ln A$. The plot of Figure 7 yields in an activation energy of $134 \mathrm{~kJ} / \mathrm{mol}$. The frequency factor $A=1.27 \times 10^{10} \mathrm{~s}^{-1}$ was computed from the $\mathrm{y}$ intercept. This activation is slightly higher (although perhaps not significantly) than most of the reported activation energies listed in Section 1 for isothermal decomposition. Perhaps more significantly, this study deduced that the nickel hydroxide decomposition obeyed first-order kinetics, not a contracting area/volume mechanism as other isothermal kinetic studies reported [19, 21]. Sample size could certainly affect the observed mechanism. El-Salaam and Hassan [19] used a much larger sample size (500 mg) than our study $(10 \mathrm{mg}$ ), so differing observed mechanisms would not be unexpected.

However, Swaddle and Wong [21] used similar sized sample mass as this study, and still reported a contracting area/volume reaction model. The study by Swaddle and Wong did not appear to consider a great number of possible reaction mechanisms, nor did it perform any visual analysis or further study in an attempt to identify a mechanism, so perhaps a first-order decay fit their data equally well, but was not considered. The focal point of the Swaddle and Long study was to investigate the hydrothermal decomposition of nickel oxide, so dry nickel hydroxide decomposition tests were only performed for comparison, and not for the detailed study of the dry decomposition process itself. While most of the literature studies as well as our study observed a deceleratory reaction, Gabr et al. [22] conversely reported acceleratory behavior along with a nucleation and growth mechanismm, along with a much higher activation energy. The temperature range for their study was somewhat higher than most of the other literature studies, $250-350^{\circ} \mathrm{C}$, and the authors reported (and modelled) significant sintering above $310^{\circ} \mathrm{C}$. Increased sintering would result in more compacted particles with fewer available pathways for product water. In fact, the authors did observe product water escape inhibition, which along with the 
increased reaction temperatures and particle sintering might have contributed to their elevated activatio0n energy and acceleratory reaction behavior.

Solid state thermal decomposition reactions are sensitive to differences in atmosphere, particle size, preparation method, etc. which could have all contributed to the differences in kinetics constants between this and reported studies. The TGA used in the present study uses a static $99.999 \%$ helium atmosphere, 0.1 bar above atmospheric pressure, in contrast to most TGA systems that use a dynamic flowing gas environment. This static environment results in product water vapor not being swept away from the surface of the particles. Brownian motion is responsible for moving product water vapor away from the sample, a slower transfer mechanism than convection. In the TGA for this study, the sample was in a relatively large cup, which might further slow the transfer of water vapor away from the sample. These factors result in a local increased water vapor concentration in the static atmosphere above the nickel hydroxide sample, potentially suppressing continued reaction of Eqn. (1), which could result in both our higher than reported activation energies as well as the drastic reaction rate slowing at elevated conversions. This local increased water vapor concentration could explain the apparent decrease in conversion observed following maximum conversion attainment for the higher temperature data in Figure 3. Rehydration/adsorption of this excess water back onto the nickel oxide product particles would increase the TGA mass loading on the sample, thus falsely decreasing the computed conversion values as per Eqn. (4). The rehydrated/adsorbed water would not be visible in the product XRD spectra in Figure 4. Thus, the authors conclude that complete conversion was prevented by the presence of product water either trapped within the TGA crucible enveloping the particle matrix or the particle matrix itself. This presence of this water both suppressed the reaction rate at elevated conversions as well as prevented complete conversion. Accordingly, the differences between the kinetic parameters computed in this study (listed above) and those reported elsewhere were thought to be caused in part by the continued presence of product water vapor within the TGA due to the static environment slightly suppressing the decomposition reaction.

Evidence for this reaction suppression due to product water retention near full conversion can be found in both the non-isothermal and isothermal data. Figure 2 shows how the reaction rate slows even as the temperature continuously rises. The highest temperature runs for both isothermal data sets in Figure 3 show that the reaction nearly stops at conversions of $90-95 \%$. This reaction slowing effect has often been observed in the literature, although the effect is not always addressed [9-11, 29, 30]. Gabr et al. proposed water escape inhibition at higher temperatures and conversions [22]. Hazell and Irving proposed that adsorbed water masks continued reaction measured by mass change above $60 \%$ conversion based upon IR absorption data [20]. Logvinenko et al. explained the slowing of the reaction as the result of trapped water within the lattice and steric hindrance of remaining residual $\mathrm{OH}^{-}$groups [23]. Based upon our results and other literature studies, nickel hydroxide certainly appears to be a substance that remains attached in some form to its product water, which then tends to suppress continued thermal decomposition.

\subsection{Isothermal-B Model Fitting (100 mg sample mass)}


None of the 17 tested decomposition models acceptably fit the Isothermal-B data - the larger sample size $(\sim 100 \mathrm{mg})$, indicating at the least that the larger sample size affects the reaction mechanism. A likely explanation would be the presence of a multistep reaction. Further study would be required for a more in-depth and thorough treatment of a multistep reaction model. However, there is some evidence for a two-step decomposition model. The reaction rate plots in Figure 6 exhibit exponential decay shaped curves up to conversions of $\sim 40-60 \%$ that correspond to diffusion based models, or perhaps higher order reaction models. For the single reactant thermal decomposition of this study, a higher reaction of order model would be unexpected. With a larger sample mass for the Isothermal-B data, the product water exit pathways out of the sample (within the TGA crucible) would be expected to be longer than for the smaller $10 \mathrm{mg}$ nominal sample size, thus leading to bulk diffusion of product water out of the sample mass limiting further decomposition. However, above conversions values of 40$60 \%$, the reaction rate plot becomes linear and still deceleratory - indicative of first-order decomposition as was observed for the smaller $10 \mathrm{mg}$ nominal sample size data.

As seen in Figure 6, the reaction is deceleratory after the initial, short acceleratory phase. Eventually, the reaction rate, and thus water production, slows down enough so that product water diffusion out of the sample mass is not limiting. Once this occurs, the reaction is only limited by nickel hydroxide availability and obeys the first-order kinetics observed with the smaller sample mass data. Additionally, since no significant particle sintering or coalescence was observed in Figure 5, particle porosity must be increasing due to the vacating water species, thus allowing increased product water exit pathways and reducing the effect of diffusion limitation. Note that for the $190^{\circ} \mathrm{C}$ data (the lowest temperature studied), the reaction rate is linear even at low conversions. The overall reaction rate is much slower at this temperature, so product water production would also be slow - slow enough to be more limiting than water exit diffusion. Thus, first-order kinetics could successfully fit nearly all of the decomposition at lower temperatures. These are just proposed mechanisms; a more in-depth study of this apparent multi-step reaction mechanism would be required for a more complete understanding of larger sample mass nickel hydroxide thermal decomposition.

The present study is the first one targeting the phase relationship of $\mathrm{Ni}$-rich $\mathrm{Ni}-\mathrm{O}-\mathrm{H}$ system at lower temperatures. Because of the limitation of experimental facilities, the nickel oxy-hydroxides (namely $\mathrm{HNi}_{2} \mathrm{O}_{3}$ and $\mathrm{HNiO}_{2}$ ) were ignored. Only $\beta-\mathrm{Ni}(\mathrm{OH})_{2}$ was examined in the present study; others were addressed in a review article [31]. Those three bulk compositions whose decomposition kinetics were documented in Section 2 are marked in Figure 1. They cover wide composition ranges within the presumed $\mathrm{Ni}-\mathrm{Ni}(\mathrm{OH})_{2}-\mathrm{NiO}$ Gibbs phase triangle.

Representative $x$-ray diffraction spectra from the annealing tests are presented in Figure 8. Only results from $\mathrm{Ni}_{50} \mathrm{O}_{30} \mathrm{H}_{20}$ are presented, since results from all three annealed compositions were similar. The $\mathrm{Ni}_{50} \mathrm{O}_{30} \mathrm{H}_{20}$ spectrum pre-annealing shows the three mixed phases: nickel, nickel oxide, and nickel hydroxide. After annealing, the nickel hydroxide phase is lost, leaving behind only nickel and nickel oxide. No new phases were observed. There was almost no annealing temperature effect on the diffraction scans. The annealed samples did appear to be more crystalline than the initial samples due to the increased sharpness of the diffraction peaks, perhaps simply due to the essential removal of water via nickel oxide decomposition. 
The consistence in their decomposition behavior during isothermal annealing and the corresponding XRD pattern during various stages of their decomposition, indicate that they decompose via the same reaction. That is, $\beta-\mathrm{Ni}(\mathrm{OH})_{2}$ decomposes to water vapor and $\mathrm{NiO}$ quickly, and there was no reaction between $\mathrm{Ni}(\mathrm{OH})_{2}$ and $\mathrm{Ni} / \mathrm{NiO}$. In other words, no "new" phase was observed within this triangle. This confirms the $\mathrm{Ni}-\mathrm{Ni}(\mathrm{OH})_{2}-\mathrm{NiO}$ phase triangle proposed by Huggins [27] below the decomposition temperature of $\mathrm{Ni}(\mathrm{OH})_{2}$, which is about $230^{\circ} \mathrm{C}$. The isotherm at $\mathrm{T}=25^{\circ} \mathrm{C}$ is shown in Figure 1. The isotherm was calculated using the CALPHAD method [32]. The Gibbs free energy of individual phases was optimized based on experimental information data on phase diagrams and thermochemistry pertaining to the $\mathrm{Ni}-\mathrm{O}-\mathrm{H}$ system.

\section{Conclusions}

A study on the decomposition kinetics of nickel (II) hydroxide powder was carried out combining thermogravimetric measurements and various kinetics models. The phase equilibria in the Ni-rich corner at low temperature were also investigated. Image analysis indicated that no significant size or morphological changes occurred during the decomposition process. Based upon numerical model fitting of the data and the imaging, a first-order random nucleation model was proposed, as opposed to diffusion and moving-boundary models reported by others. At larger TGA sample mass loadings, the reaction appeared to obey a multi-step diffusion/first-order combined mechanism, presumably due to the increased exit path length for product $\mathrm{H}_{2} \mathrm{O}$ at higher sample loadings. The activation energy and frequency factor for the 10-mg nominal sample size (Isothermal-A) data set were measured as $E_{a}=134$ $\mathrm{kJ} / \mathrm{mol}$ and $A=1.27 \times 10^{10} \mathrm{~s}^{-1}$, respectively.

$\beta-\mathrm{Ni}(\mathrm{OH})_{2}$ decomposed to water vapor and $\mathrm{NiO}$ quickly, indicating that there was no reaction between $\mathrm{Ni}(\mathrm{OH})_{2}$ and $\mathrm{Ni} / \mathrm{NiO}$. This confirms the $\mathrm{Ni}-\mathrm{Ni}(\mathrm{OH})_{2}-\mathrm{NiO}$ phase triangle. Thus, a thermodynamic description of the system was established in the Ni-rich corner, and the isotherm at room temperature was calculated. Annealing experiments from $210-230^{\circ} \mathrm{C}$ of the $\mathrm{Ni}-\mathrm{Ni}(\mathrm{OH})_{2}-\mathrm{NiO}$ phase triangle within $\mathrm{Ni}-$ $\mathrm{O}-\mathrm{H}$ system yielded only two phases: nickel and nickel oxide, with no new phases formed.

\section{Acknowledgements}

This work was funded by the Cross-Cutting Technologies Program at NETL. The research was executed through NETL Office of Research and Development's Innovative Process Technologies (IPT) Field Work Proposal, as part of Task 5, "Computational Materials." Research conducted by AECOM Staff was conducted under the RES contract DE-FE-0004000. This project was funded by the Department of Energy, National Energy Technology Laboratory, an agency of the United States Government, through a support contract with AECOM. Neither the United States Government nor any agency thereof, nor any of their employees, nor AECOM, nor any of their employees, makes any warranty, expressed or implied, or assumes any legal liability or responsibility for the accuracy, completeness, or usefulness of any information, apparatus, product, or process disclosed, or represents that its use would not infringe 
privately owned rights. Reference here in to any specific commercial product, process, or service by trade name, trademark, manufacturer, or otherwise, does not necessarily constitute or imply its endorsement, recommendation, or favoring by the United States Government or any agency thereof. The views and opinions of authors expressed herein do not necessarily state or reflect those of the United States Government or any agency thereof.

\section{References}

[1] A. Ayeb, P.H.L. Notten, The oxygen evolution kinetics in sealed rechargeable NiMH batteries, Electrochim. Acta, 53 (2008) 5836-5847, 10.1016/j.electacta.2008.03.023.

[2] C. Fierro, A. Zallen, J. Koch, M.A. Fetcenko, The influence of nickel-hydroxide composition and microstructure on the high-temperature performance of nickel metal hydride batteries, J. Electrochem. Soc., 153 (2006) A492-A496, 10.1149/1.2161577.

[3] T.A. Han, J.P. Tu, J.B. Wu, Y. Li, Y.F. Yuan, Electrochemical properties of biphase $\mathrm{Ni}(\mathrm{OH}) 2$ electrodes for secondary rechargeable Ni/MH batteries, J. Electrochem. Soc., 153 (2006) A738-A742, 10.1149/1.2171829.

[4] C.J. Liu, Y.W. Li, Synthesis and characterization of amorphous alpha-nickel hydroxide, J. Alloys Comp., 478 (2009) 415-418, 10.1016/j.jallcom.2008.11.049.

[5] J.Y. Liu, Y. Ren, B. Dasgupta, H. Tanoto, H.L. Seng, W.K. Chim, S.F.Y. Li, S.Y. Chiam, The role of ions and reaction sites for electrochemical reversible charge cycling in mesoporous nickel hydroxides, J. Mater. Chem. A, 1 (2013) 15095-15101, 10.1039/c3ta13938g.

[6] S.R. Ovshinsky, M.A. Fetcenko, J. Ross, A nickel metal hydride battery for electric vehicles, Sci., 260 (1993) 176-181, 10.1126/science.260.5105.176.

[7] N. SacEpee, M.R. Palacin, B. Beaudoin, A. DelahayeVidal, T. Jamin, Y. Chabre, J.M. Tarascon, On the origin of the second low-voltage plateau in secondary alkaline batteries with nickel hydroxide positive electrodes, J. Electrochem. Soc., 144 (1997) 3896-3907, 10.1149/1.1838108.

[8] E.B. Shangguan, Z.R. Chang, H.W. Tang, X.Z. Yuan, H.J. Wang, Regulation of the discharge reservoir of negative electrodes in Ni-MH batteries by using $\mathrm{Ni}(\mathrm{OH})(\mathrm{x})(\mathrm{x}=2.10)$ and gamma-CoOOH, J. Power Sources, 196 (2011) 7791-7796, 10.1016/j.jpowsour.2011.05.012.

[9] Z.H. Liang, Y.J. Zhu, X.L. Hu, Beta-nickel hydroxide nanosheets and their thermal decomposition to nickel oxide nanosheets, J. Phys. Chem. B, 108 (2004) 3488-3491, 10.1021/jp037513n.

[10] Q. Dong, S. Yin, C.S. Guo, X.Y. Wu, N. Kumada, T. Takei, A. Miura, Y. Yonesaki, T. Sato, Singlecrystalline porous $\mathrm{NiO}$ nanosheets prepared from beta- $\mathrm{Ni}(\mathrm{OH})_{2}$ nanosheets: Magnetic property and photocatalytic activity, Appl. Catal. B - Environ., 147 (2014) 741-747, 10.1016/j.apcatb.2013.10.007.

[11] C.Y. Li, S.X. Liu, Preparation and characterization of $\mathrm{Ni}(\mathrm{OH})_{2}$ and $\mathrm{NiO}$ mesoporous nanosheets, J. Nanomater., (2012), 10.1155/2012/648012.

[12] M. Salavati-Niasari, M. Entesari, Controlled synthesis of spherical alpha-Ni(OH $)_{2}$ hierarchical nanostructures via a simple hydrothermal process and their conversion to NiO, Polyhedron, 33 (2012) 302-309, 10.1016/j.poly.2011.11.054.

[13] X.F. Song, L. Gao, Facile route to nanoporous $\mathrm{NiO}$ structures from the alpha-Ni(OH)$)_{2} / \mathrm{EG}$ precursor and application in water treatment, J. Am. Ceram. Soc., 91 (2008) 4105-4108, 10.1111/j.15512916.2008.02762.x.

[14] A. Tang, X. Li, Z.T. Zhou, J. Ouyang, H. Yang, Mechanochemical synthesis of $\mathrm{Ni}(\mathrm{OH})_{2}$ and the decomposition to NiO nanoparticles: Thermodynamic and optical spectra, J. Alloys Comp., 600 (2014) 204-209, 10.1016/j.jallcom.2014.02.120. 
[15] Z.R. Suo, X.N. Dong, H. Liu, Single-crystal-like NiO colloidal nanocrystal-aggregated microspheres with mesoporous structure: Synthesis and enhanced electrochemistry, photocatalysis and water treatment properties, J. Solid State Chem., 206 (2013) 1-8, 10.1016/j.jssc.2013.07.026.

[16] G.H. Li, X.W. Wang, H.Y. Ding, T. Zhang, A facile synthesis method for $\mathrm{Ni}(\mathrm{OH})_{2}$ ultrathin nanosheets and their conversion to porous $\mathrm{NiO}$ nanosheets used for formaldehyde sensing, RSC Adv., 2 (2012) 13018-13023, 10.1039/c2ra22049k.

[17] A.K. Galwey, M.E. Brown, Thermal Decomposition of Ionic Solids, Elsevier Science, Amsterdam, 1999.

[18] A. Khawam, D.R. Flanagan, Solid-state kinetic models: Basics and mathematical fundamentals, J. Phys. Chem. B, 110 (2006) 17315-17328, 10.1021/jp062746a.

[19] K.M.A. El-Salaam, E.A. Hassan, A study of the effect of lithium and aluminum on the thermaldecomposition of nickel-hydroxide, Surf. Technol., 11 (1980) 55-60, 10.1016/0376-4583(80)90018-7.

[20] I.F. Hazell, R.J. Irving, Thermal decomposition of iron(II) cobalt(II) and nickel(II) hydroxides, (1966) $669,10.1039 / \mathrm{j} 19660000669$.

[21] T.W. Swaddle, T.C.T. Wong, Hydrothermal reaction kinetics. The decomposition of nickel(II) hydroxide, 56 (1978) 363-369, 10.1139/v78-058.

[22] R.M. Gabr, A.N. Elnaimi, M.G. Althani, Effect of thermal-treatment on the kinetics and sintering characteristics of nickel-hydroxide as a precursor for the thermal genesis of nickel-oxide catalyst, Thermochim. Acta, 197 (1992) 307-318, 10.1016/0040-6031(92)85029-u.

[23] V. Logvinenko, V. Bakovets, L. Trushnikova, Decomposition processes of nickel hydroxide, J. Therm. Anal. Calorim., 107 (2012) 983-987, 10.1007/s10973-011-1689-0.

[24] ASTM, Standard test method for Arrhenius kinetic constants for thermally unstable materials using differential scanning calorimetry and the Flynn/Wall/Ozawa method, in, ASTM International, West Conshohocken, PA, 2011.

[25] ASTM, Standard test method for estimating kinetic parameters by differential scanning calorimeter using the Borchardt and Daniels method, in, ASTM International, West Conshohocken, PA, 2013.

[26] C.S. Giggins, F.S. Pettit, OXIDATION OF NI-CR-AL ALLOYS BETWEEN 1000 DEGREES AND 1200 DEGREES C, 118 (1971) 1782-\&, 10.1149/1.2407837.

[27] R.A. Huggins, Mechanism of the memory effect in "nickel" electrodes, 177 (2006) 2643-2646, 10.1016/j.ssi.2006.03.005.

[28] D. Balzar, N.C. Popa, Analyzing Microstructure by Rietveld Refinement, 22 (2005) 16-25.

[29] M.M.K. Motlagh, A.A. Youzbashi, F. Hashemzadeh, L. Sabaghzadeh, Structural properties of nickel hydroxide/oxyhydroxide and oxide nanoparticles obtained by microwave-assisted oxidation technique, Powder Technol., 237 (2013) 562-568, 10.1016/j.powtec.2012.12.047.

[30] T.N. Ramesh, X-ray diffraction studies on the thermal decomposition mechanism of nickel hydroxide, J. Phys. Chem. B, 113 (2009) 13014-13017, 10.1021/jp906578u.

[31] P. Oliva, J. Leonardi, J.F. Laurent, C. Delmas, J.J. Braconnier, M. Figlarz, F. Fievet, A. Deguibert, Review of the structure and the electrochemistry of nickel hydroxides and oxy-hydroxides, J. Power Sources, 8 (1982) 229-255, 10.1016/0378-7753(82)80057-8.

[32] N. Saunders, A.P. Miodowink, CALPHAD (Calculation of Phase Diagrams): A Comprehensive Guide, Pergamon, Oxford, 1998. 


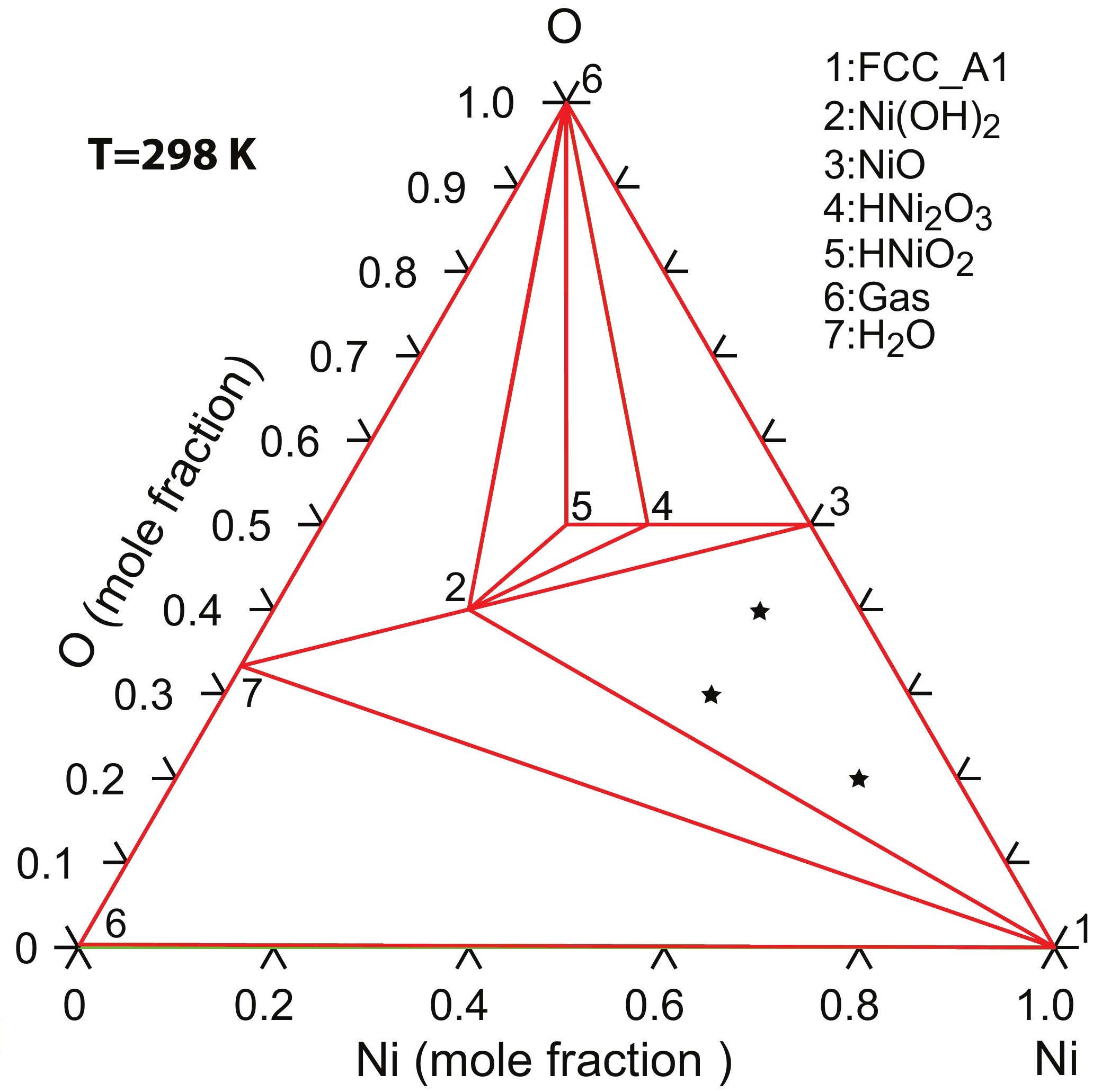


Caption1

Figure 1. Calculated $\mathrm{Ni}-\mathrm{O}-\mathrm{H}$ isotherm at $\mathrm{T}=23^{\circ} \mathrm{C}$ using CALPHAD method [31] based on the present study and Huggins [26]. The stars signify the three bulk compositions whose decomposition kinetics were studied. 


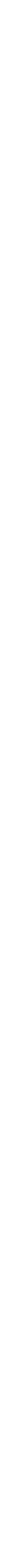


Caption2
\[ \text { Figure 2. Non-isothermal TGA mass traces at a heating rate of } 5^{\circ} \mathrm{C} / \mathrm{min} \text {. } \]

Caption2
\[ \text { Figure 2. Non-isothermal TGA mass traces at a heating rate of } 5^{\circ} \mathrm{C} / \mathrm{min} \text {. } \]

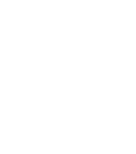

.

(1) 


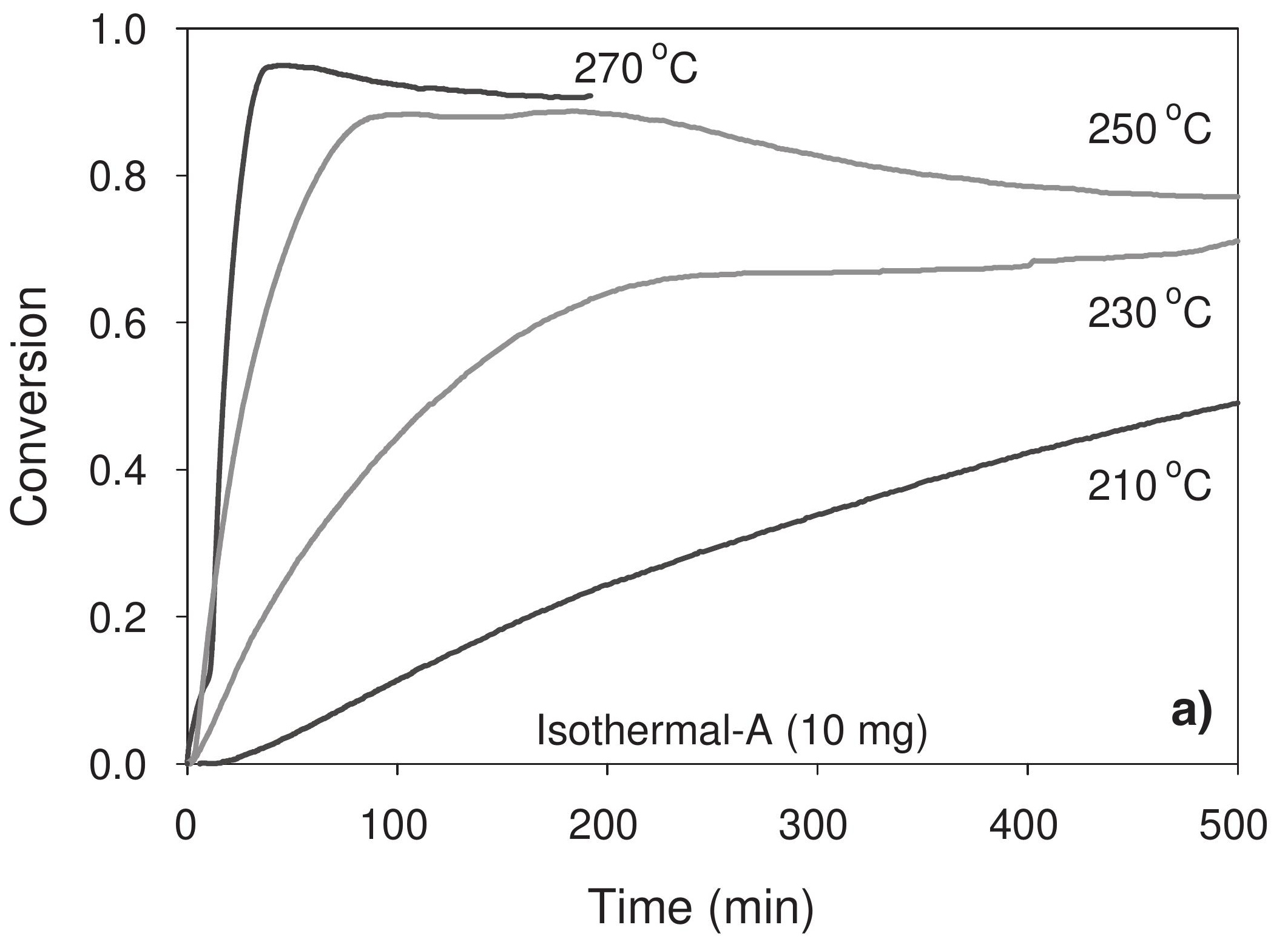


Caption3

Figure 3. TGA conversion trace for both data sets.

Figure 3. TGA conversion trace for both data sets.

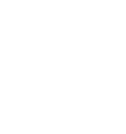

Figure 3. TGA conversion trace for both data sets.

$\left(\frac{10}{20}\right.$

Figure 3. TGA conversion trace for both data sets.

(1)

(1)

(1)

Figure 3. TGA conversion trace for both data sets.

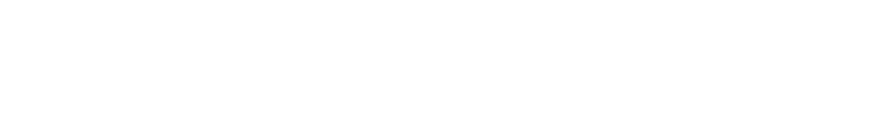

(1)

$\sqrt{2}$

Figure 3. TGA conversion trace for both data sets.

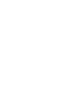

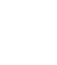

(1)

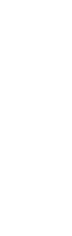

(1)

(1)

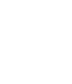

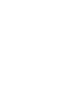

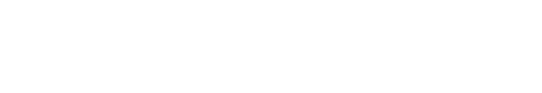

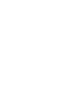

(n)

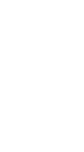

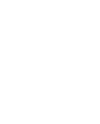

- 
Figure 4. X-ray diffraction scans of $\mathrm{Ni}(\mathrm{OH})_{2}$ powder before and after Isothermal-B TGA scans. 

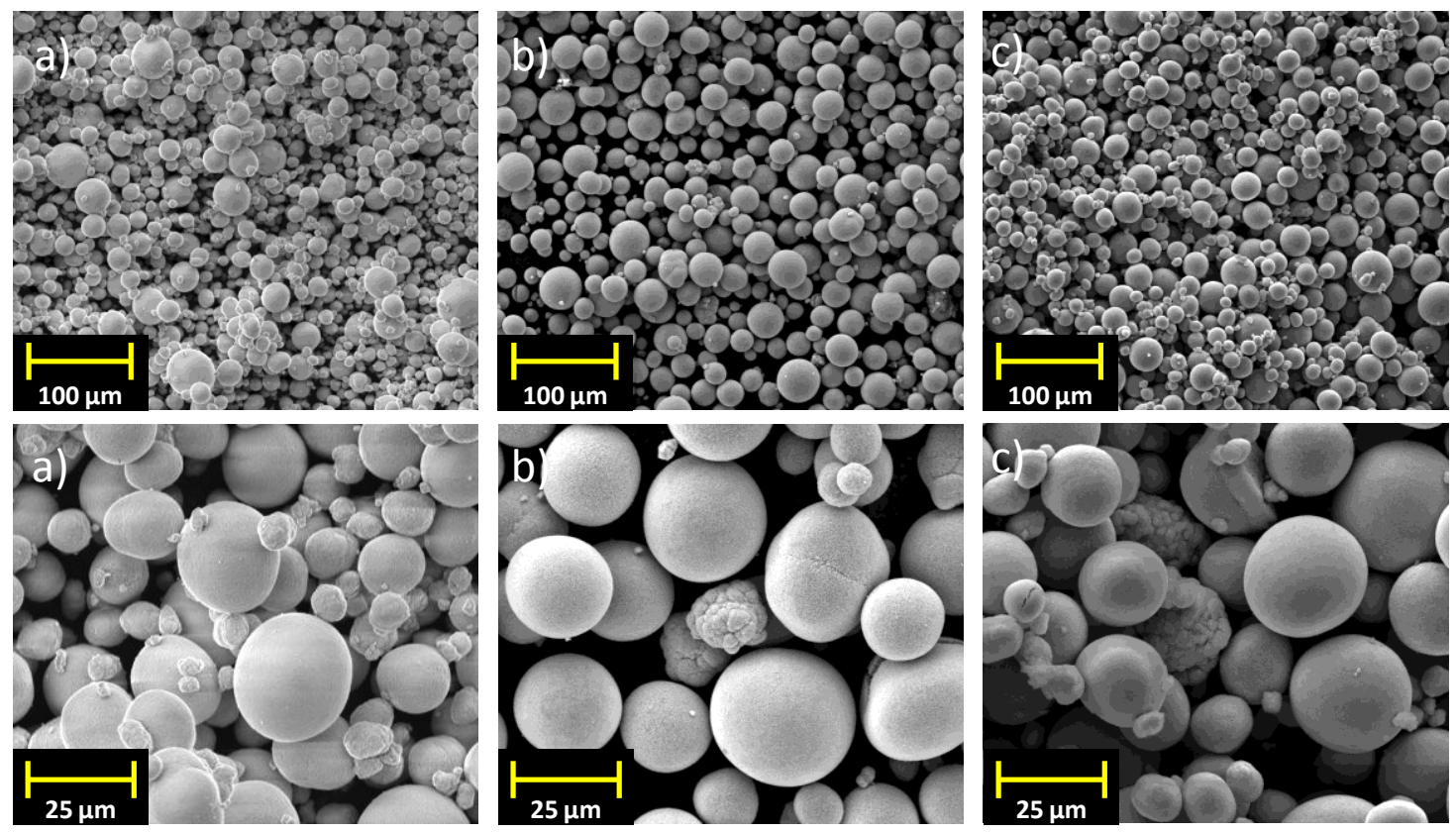

Figure5 
Caption5

Figure 5. SEM micrographs of: a) feed $\mathrm{Ni}(\mathrm{OH})_{2}$. b) Partially converted (56\%) Isothermal-B TGA product obtained by a 2-hour isothermal hold at $200^{\circ} \mathrm{C}$. c) Nearly fully converted (92\%) Isothermal-B TGA product obtained by a 2-hour isothermal hold at $250^{\circ} \mathrm{C}$. 


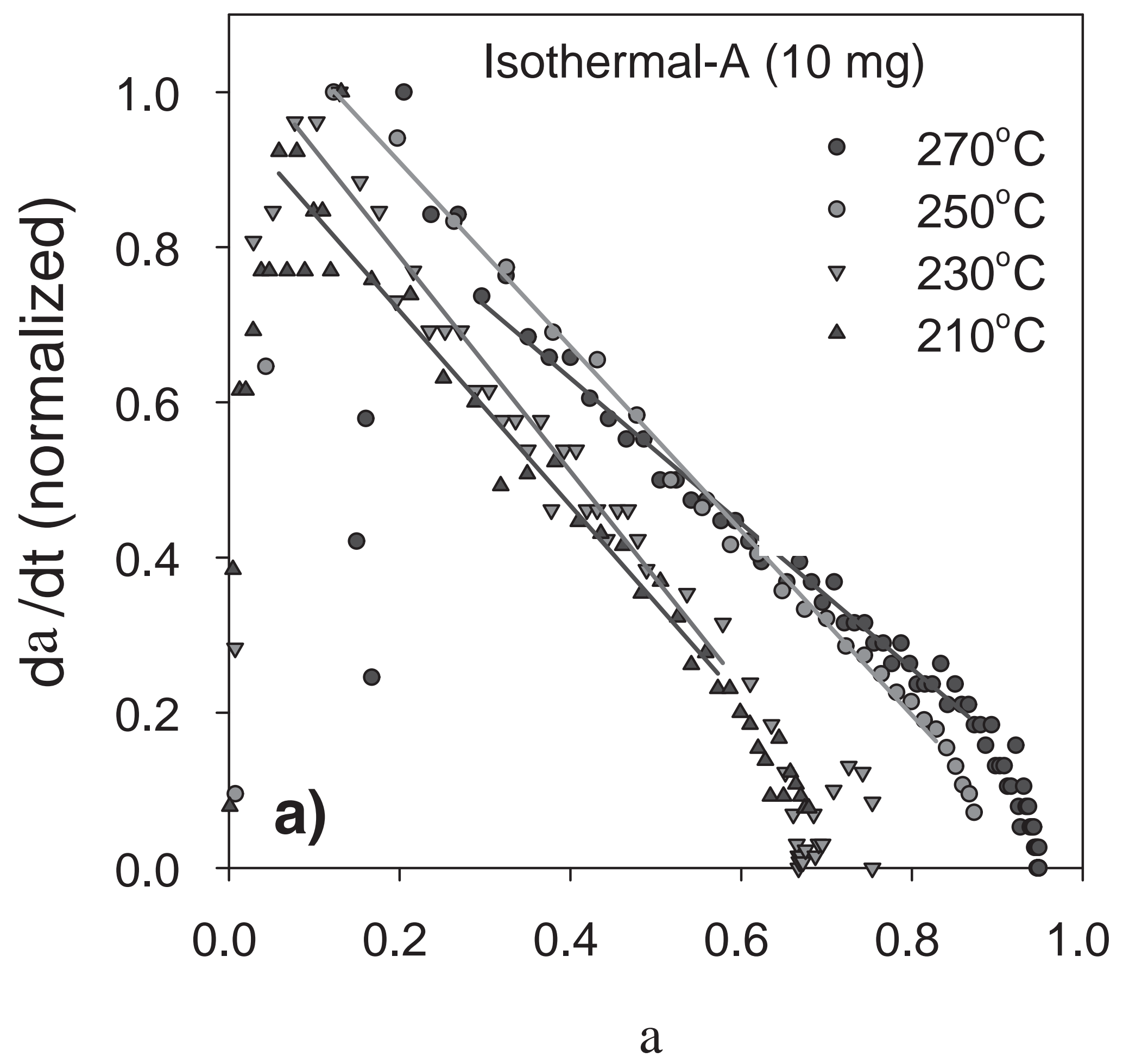


Figure 6. Reaction rate plots for both data sets.

Caption6

Figure 6. Reaction rate plots for both data sets.

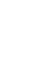

. Reaction rate plots for both data sets.

(n)
$\sqrt{2}$

(1)

(1)

Figure

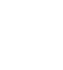

(1)

(1)

(1)

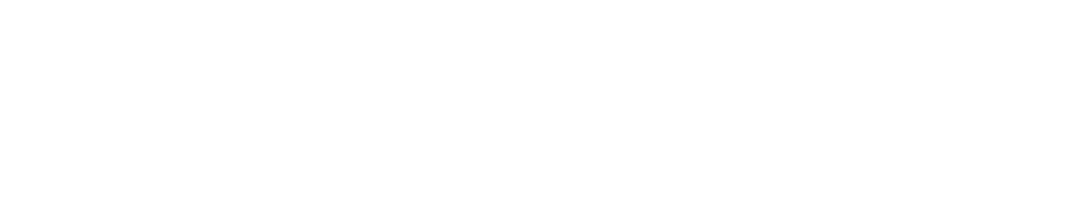

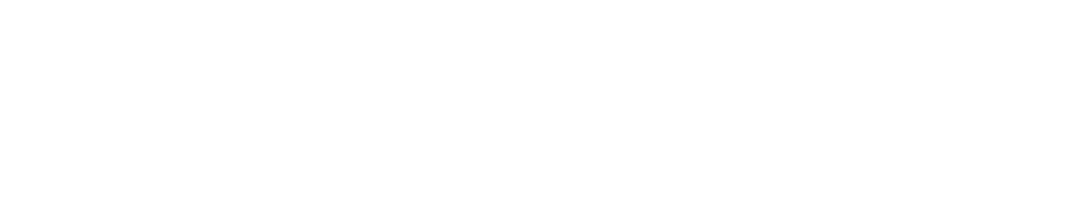

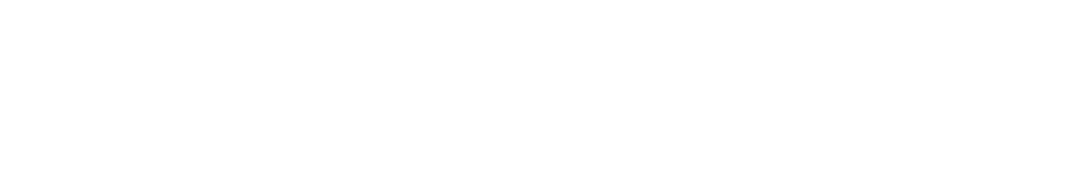

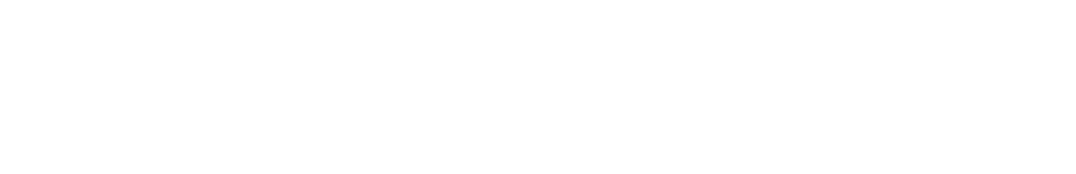

(1)

(1)

(1)

(1)

(1) 


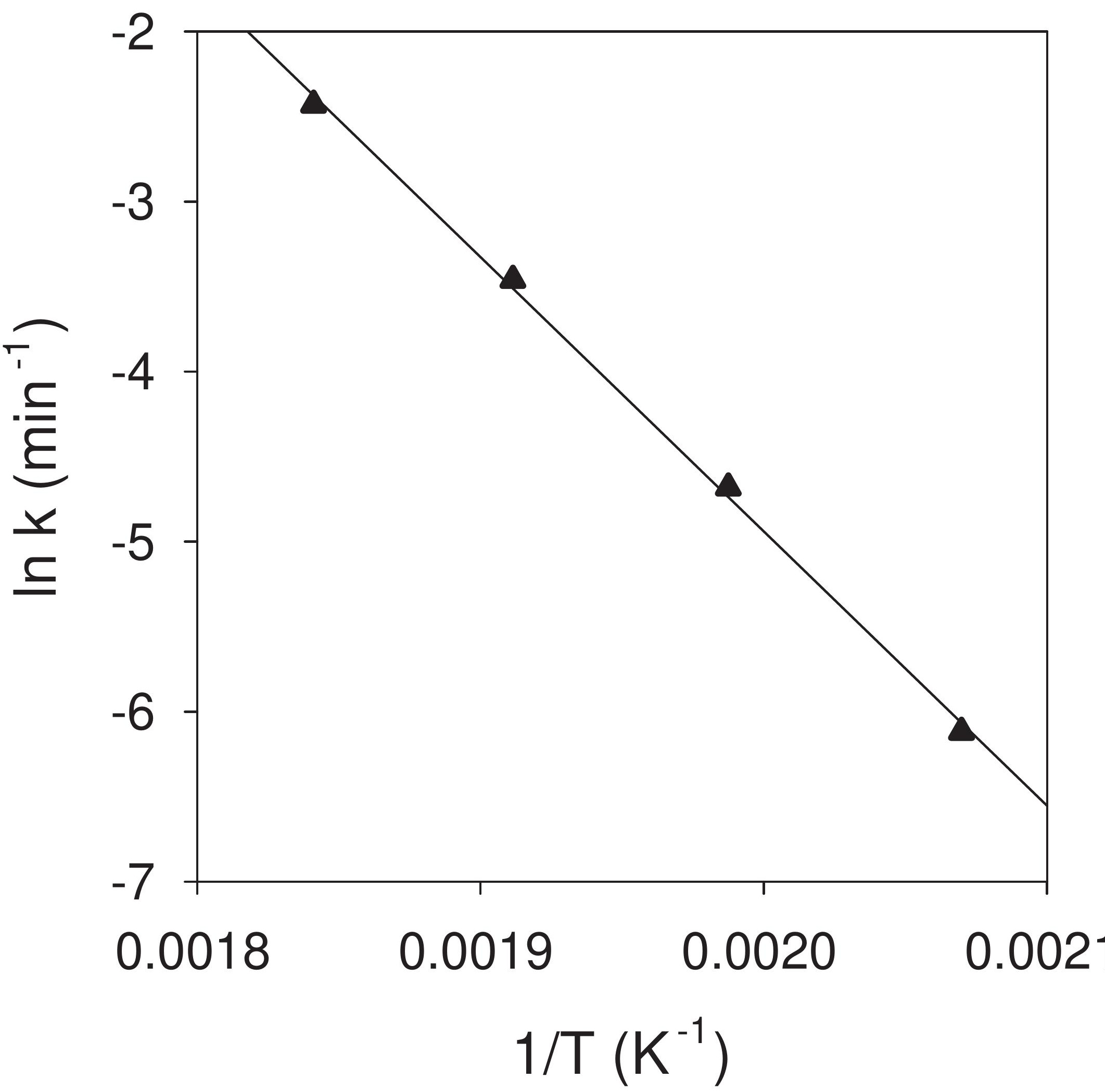




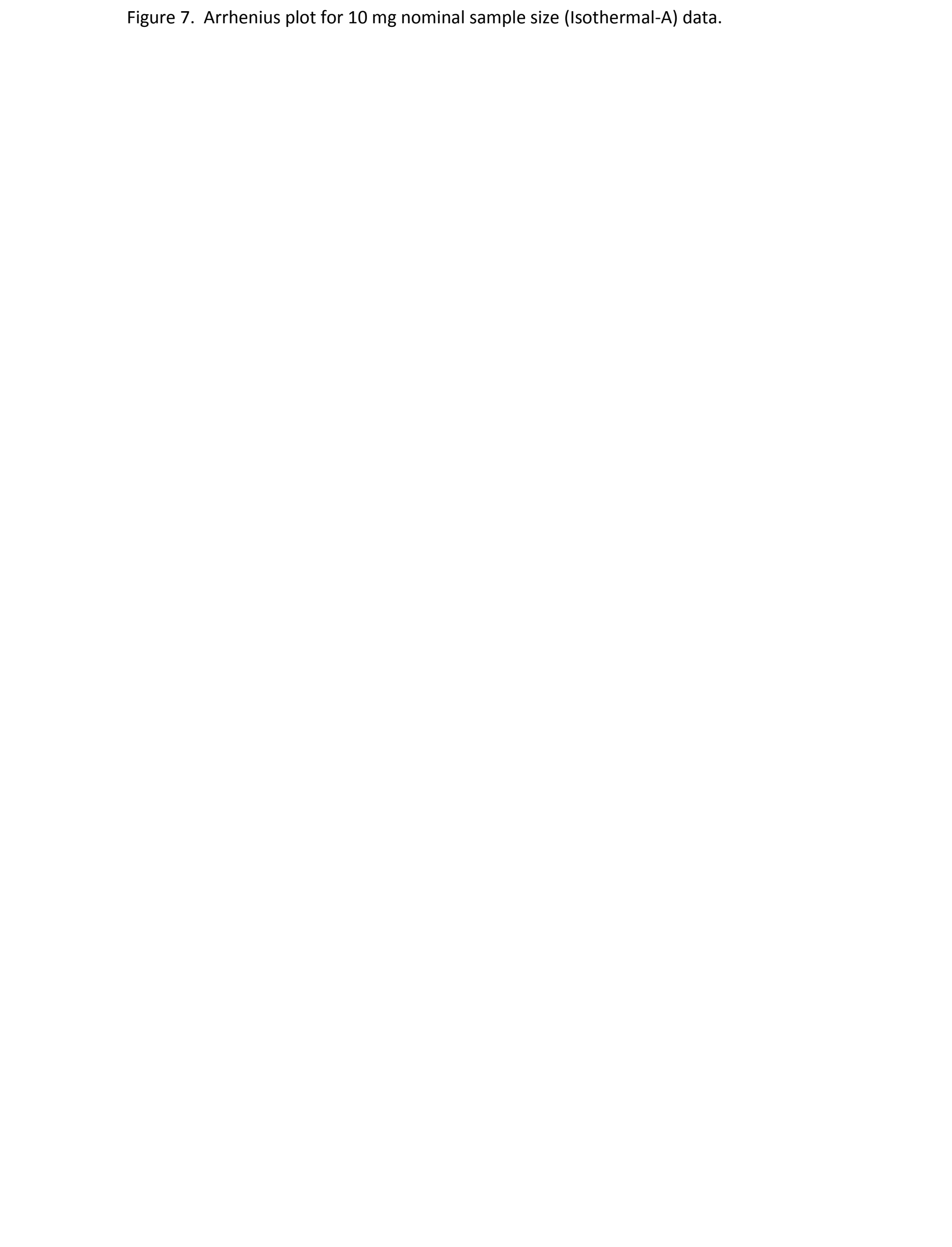

Caption7

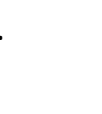

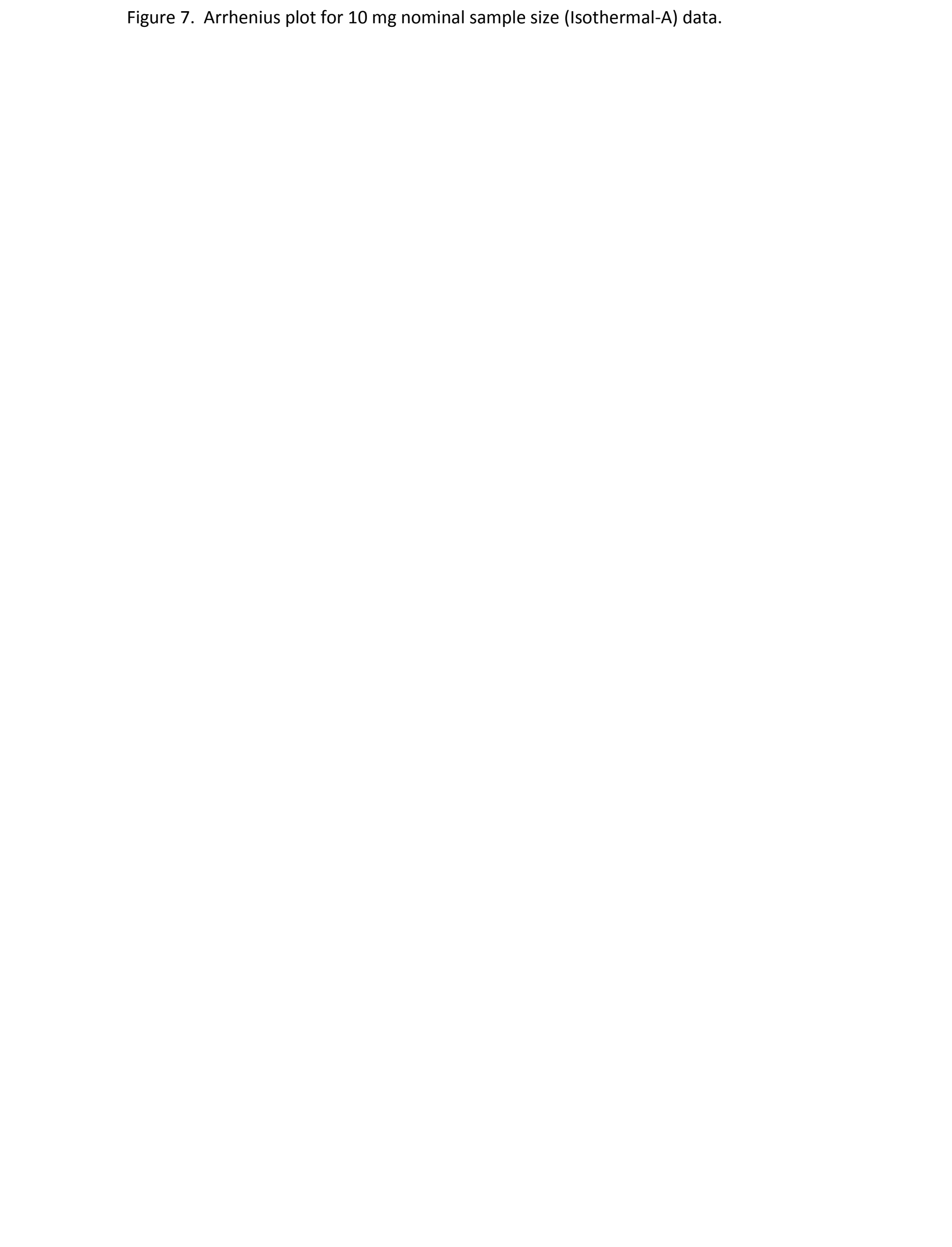

Figure 7. Arrhenius plot for $10 \mathrm{mg}$ nominal sample size (Isothermal-A) data.

Figure 7. Arrhenius plot for $10 \mathrm{mg}$ nominal sample size (Isothermal-A) data.

Figure 7. Arrhenius plot for $10 \mathrm{mg}$ nominal sample size (Isothermal-A) data.

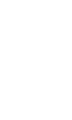

.

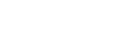

(1)

(1)

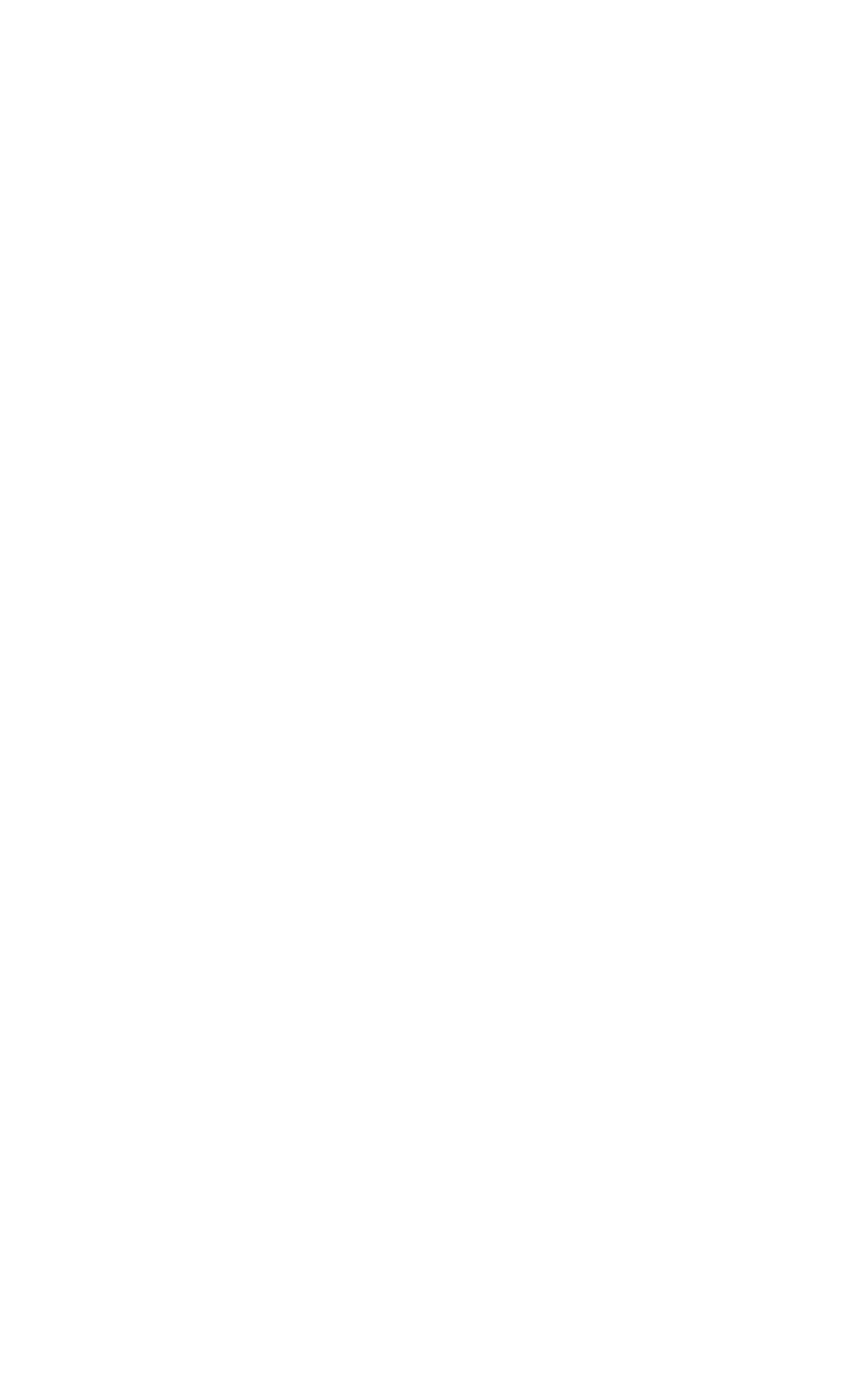


Caption8

Figure 8. X-ray diffraction scans of annealing tests of the $\mathrm{Ni}_{50} \mathrm{O}_{30} \mathrm{H}_{20}$ composition.

Figure 8. X-ray diffraction scans of annealing tests of the $\mathrm{Ni}_{50} \mathrm{O}_{30} \mathrm{H}_{20}$ composition.

(n)

\section{Caption}

Figure 8. X-ray diffraction scans of annealing tests of the $\mathrm{Ni}_{50} \mathrm{O}_{30} \mathrm{H}_{20}$ composition.

Figure 8. X-ray diffraction scans of annealing tests of the $\mathrm{Ni}_{50} \mathrm{O}_{30} \mathrm{H}_{20}$ composition.

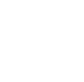

.

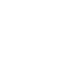

